\section{Acabou o tempo dos mitos? Uma historiografia caxinauá moderna}

\author{
Por Sabine Reiter \\ Universidade Federal do Pará \\ (sabine_reiter@yahoo.com)
}

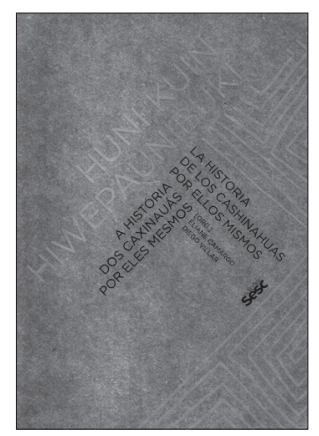

CAMARGO, Eliane; VILLAR, Diego (Org.). Huni kuin hiwepaunibuki: a história dos caxinauás por eles mesmos. La historia de los cashinahuas por ellos mismos. São

Paulo: Edições SESC, 2013. 304 p. ISBN 97885-7995-071-1

O livro "Huni kuin hiwepaunibuki: a história dos caxinauás por eles mesmos" é uma coletânea trilíngue (em caxinauá', português e espanhol) de textos com relatos sobre o passado remoto e mais recente dessa etnia indígena que vive na região fronteiriça entre o Brasil e o Peru. Foi organizado por Eliane Camargo e Diego Villar, uma linguista e um antropólogo, em colaboração com Texerino Capitán e Alberto Toríbio, dois caxinauás de diferentes comunidades do rio Purus, localizadas no lado peruano da fronteira. Com cerca de 2.400 integrantes, o grupo étnico no Peru é menos extenso em número do que seus mais de 7.500 parentes no lado brasileiro, mas - devido ao maior isolamento na primeira metade do século $X X$ - todos ainda falam a língua nativa, comparados aos caxinauás brasileiros, entre os quais há uma parte que fala apenas português².

Apesar da presença de missionários em suas aldeias, a partir dos anos 1960, os caxinauás peruanos também conseguiram manter viva maior parte da cultura tradicional, enquanto, no Acre, os caxinauás - que conviviam com uma população não indígena nos seringais desde a época da borracha - perderam quase por completo os antigos costumes. Foi nesse grupo peruano que Camargo começou a pesquisar há mais de 25 anos e, principalmente, entre 2006 e 2011, quando levantou e arquivou dados de língua e cultura desse povo no âmbito do programa Documentation of Endangered Languages (DOBES, 2000-2016), com projeto de documentação sediado no Instituto Max-Planck de Antropologia Evolutiva (MPI-EVA), em Leipzig, e na Université X de Paris, em Nanterre (DOBES, 2000-2016).

Neste livro, publicado em 2013, Camargo foi responsável pelas transcrições e traduções ao português dos textos orais, em boa parte provenientes do acervo digital do projeto DOBES. Villar, que é pesquisador adjunto do Conselho Nacional de Pesquisas Científicas e Técnicas na Argentina e especialista de culturas pano, por sua parte, responsabilizou-se pela versão espanhola dos textos. Além disso, os dois organizadores restringiram-se a elaborar algumas frases introdutórias e comentários aos textos narrativos em notas de rodapé, onde explicam ao leitor o contexto narrativo, construções linguísticas e conceitos culturais. A escolha dos textos assim como a sua edição para formato escrito, no entanto, coube a uma equipe de jovens caxinauás, coordenada por Texerino Capitán, professor de escola bilíngue, e Alberto Toríbio, principal assistente de pesquisa do projeto DOBES. O livro, como informa Bernard Comrie, então diretor do departamento de linguística do MPI-EVA, na apresentação, é um dos produtos do projeto de documentação da iniciativa DOBES, que, através da perspectiva própria de um povo, "nos fornece uma visão diferente do mundo e a compreensão de nós mesmos" (Comrie, 2013, p. 23-25). Até hoje, é uma das poucas publicações que deixa falar -

O caxinauá pertence à família linguística pano.

Esses são os números oficiais do Instituto Socioambiental (Ricardo, B.; Ricardo, F., 2011, p. 12), que divergem consideravelmente de números informados em outras fontes, por exemplo, no site Ethnologue (Lewis et al., 2016). Segundo o Ethnologue, atualmente todos os caxinauás adquirem a língua nativa. Como o nível de conhecimento da língua indígena é uma questão política no Brasil, há diferenças entre os números oficiais em relação ao que se pode observar in situ.

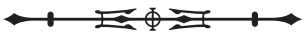


na sua totalidade - os próprios integrantes de um povo indígena amazônico.

O livro consiste em cinco partes principais. Nelas, os caxinauás informam sobre os hábitos dos seus antepassados, lembrados por alguns idosos e presentes na memória coletiva. Eles falam sobre os encontros com outras etnias pano, inclusive com aquelas encontradas pela Fundação Nacional do Índio (FUNAI) em 2008, celebradas pela mídia internacional como "os últimos selvagens" ${ }^{3}$, e sobre os primeiros contatos com os 'nauás', os outros, não indígenas de origem europeia. Relatam sobre as suas experiências em território alheio e nas grandes cidades, e sobre a história de migração e dispersão do próprio grupo, que se iniciou nos tempos míticos com uma briga entre o criador Txi Wa e seu parente Apu, e continuou com acontecimentos em consequência dos primeiros contatos com brasileiros nos seringais. $\bigcirc$ anexo que segue as partes principais do livro apresenta uma nota sobre a grafia utilizada e um léxico trilíngue extraído dos textos em caxinauá e de termos significativos.

As fontes das narrativas são diversas: cinco dos 25 textos provêm do livro "Rã-txã hu-ni kuï: grammatica, textos e vocabulário caxinauás. A lingua dos caxinauás do rio Ibuacú, affluente do Murú (Prefeitura de Tarauacá)", de João Capistrano de Abreu (1914), o historiador brasileiro que - em inícios do século $X X$ - montou uma primeira coletânea de mitos, textos históricos e de outros gêneros, em conjunto com dois jovens caxinauás da região do rio Murú, no Acre. A grande maioria dos textos é composta por depoimentos e memórias polifônicas, gravadas dos anos 1990 para cá, e informações obtidas por meio de entrevistas com pessoas mais idosas - todas do grupo peruano, um segmento da população caxinauá que fugiu de um seringal brasileiro no início do século XX. No Peru, esses caxinauás e seus descendentes viviam afastados da sociedade e só foram 'redescobertos' ao final dos anos 1940; contato que foi documentado pelo fotógrafo Harald Schultz, em 1951, constituindo um acervo de aproximadamente 80 fotografias, com imagens de uma pescaria e de uma festa.

Uma variedade de trabalhos desse fotógrafo teuto-brasileiro, mostrando cenas cotidianas daquela época, assim como imagens de objetos coletados por ele - que hoje se encontram no acervo do Museu de Arqueologia e Etnologia da Universidade de São Paulo (MAE-USP) -, ilustra o livro, junto com fotografias recentes e desenhos feitos por integrantes do grupo especialmente para esta publicação. Entre eles encontramos os kene, grafismos tradicionais reproduzidos na tecelagem, na pintura corporal, em objetos e desenhos de cenas das narrativas, da vida cotidiana e de rituais. O que chama a atenção é que esses desenhos, produzidos em várias épocas, têm uma estilização própria: veem-se pessoas e objetos 'deitados' em uma vista de pássaro, para poder mostrar mais do que seria perceptível por meio do simples olhar de um espectador humano.

Todo o material recolhido neste livro foi selecionado pela equipe caxinauá, com o intuito de informar aos seus descendentes (filhos, netos) sobre a própria cultura, sendo veiculado na própria língua, a fim de manter viva a memória e uma identidade própria, como os dois colaboradores caxinauás escrevem no seu prefácio, que termina assim: "por esse motivo quisemos elaborar este livro. Dessa forma podemos todos juntos ler e aprender claramente a tradição" (Capitán; Toribio, 2013, p. 31). Ao mesmo tempo, o livro é um passo importante em direção a uma verdadeira participação dos povos indígenas na sociedade moderna através dos seus próprios discursos. Em uma época em que presenciamos ameaça cada vez mais forte à vida tradicional de povos indígenas em toda a América Latina, é essencial que um público maior tome conhecimento da história desse grupo, a qual reflete, de maneira exemplar, desenvolvimento ocorrido em

\footnotetext{
3 Veja, por exemplo, Seidler; Lubbadeh (2008).
}

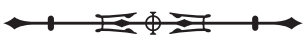


muitos outros grupos, repetindo-se até hoje. Isso ocorreu desde o primeiro contato desses povos com a sociedade nacional, representada notadamente por bandeirantes/ coronéis, soldados da borracha, viajantes, missionários e pesquisadores, resultando em interferência cultural. Nas palavras dos caxinauás (traduzidas para o português), essa interferência se lê assim: "já nos tornamos nauás com suas roupas e comida. [...] já não somos mais caxinauás! [...] O governo diz que somos todos peruanos. É assim que falam" (2013, p. 227).

Ao mesmo tempo, a citação deixa bem claro que essa é uma visão de fora, a qual não reflete necessariamente a opinião do falante. A língua pano consegue expressar essas diferentes perspectivas de maneira elegante, através de marcadores de evidencialidade (no caso, -ikiki em akikiki, 2013, p. 226) que indicam, para os membros da comunidade de fala, o compromisso epistemológico com a informação dada. Essa técnica linguística pode até ser interpretada aqui como relevante indício de uma resistência clandestina e de uma mera adaptação superficial.

Uma atitude de 'acostumação', longe de ser assimilação por completo, também se manifesta em outro depoimento. Um caxinauá descreve como chegou a trabalhar como mecânico para um missionário americano: "um dia quebrei um parafuso e ele ficou furioso. [...], achava que iria me bater. Achei isso porque me tratava assim. [...] Depois eu me acostumei com ele. [...] com suas palavras fortes" (2013, p. 203). Este trecho mostra mais um aspecto interessante do livro, a abertura para uma perspectiva intercultural: nós, os nauás, ficamos sabendo algo sobre como somos percebidos pelos caxinauás como pessoas ameaçadoras pelo simples tom da voz! Ao passo que as narrativas exibem, em diferentes partes, uma visão caxinauá, o livro em si já é uma manifestação aberta da luta para a preservação de uma identidade própria.
Comparado com outras manifestações escritas na língua caxinauá, principalmente com a obra do grande historiador brasileiro do começo do século $X X$, este livro se destaca como marcador de uma mudança na percepção e no tratamento do elemento 'indígena' na sociedade. Enquanto o livro de Capistrano possui, sobretudo, relatos míticos, este é uma historiografia, em grande parte, de fatos vividos pelos caxinauás nos últimos 100 anos. Quem escolheu o material de "Rã-txã hu-ni ku-ï" foi o próprio Capistrano, tendo os dois caxinauás como fornecedores de informação e tradutores; aqui, os agentes principais são caxinauás, que selecionaram os textos baseados em critérios de informatividade a um público caxinauá atual e jovem ${ }^{4}$. Os textos de Capistrano também já eram traduzidos para o português na época, e existia uma explicação de ortografia destinada ao leitor brasileiro erudito. Porém, aquela tradução palavra por palavra deixou o texto original parecer 'desajeitado' ao leitor brasileiro monolíngue. Certamente, não fornece uma base para ser elaborada hoje em dia na educação bilíngue indígena, já que a ortografia desenvolvida pelo historiador autodidata em linguística não reflete bem a estrutura morfofonêmica da língua, não sendo legível para os caxinauás de hoje. A mesma crítica da ortografia inadequada pode se fazer a várias publicações recentes nessa língua indígena no Brasil. A maioria dos livros em caxinauá publicada, tanto no Brasil como no Peru, porém, é dirigida ao ensino nas escolas bilíngues, enquanto este livro pode ser de interesse de um público diversificado, mono e bilíngue, jovem e adulto, estudante e professor, leigo e acadêmico, voltado aos caxinauás e a cada pessoa que tenha curiosidade de conhecer outra perspectiva do mundo. Além de valorizar a cultura caxinauá, ele representa uma restituição ao grupo de coleta de relatos históricos, efetuada por pesquisadores, contribuindo igualmente para a difusão da diversidade do patrimônio cultural imaterial da Amazônia indígena.

\footnotetext{
4 Neste contexto, pode-se questionar se o resultado realmente representa o 'olhar caxinauá', já que a equipe consiste de caxinauás escolarizados, parcialmente trabalhando na educação infantil, que, portanto, internalizaram um discurso padrão para texto escrito.
} 


\section{REFERÊNCIAS}

CAPISTRANO DE ABREU, João. Rã-txa hu-ni-ku-ï: grammatica, textos e vocabulário caxinauás. A lingua dos caxinauás do rio Ibuacú, affluente do Murú (Prefeitura de Tarauacá). Rio de Janeiro: Sociedade Capistrano de Abreu, 1914.

CAPITÁN, Tescerino Kirino; TORIBIO, Alberto Roque. Prefácio. In: CAMARGO, Eliane. VILLAR, Diego (Org.). Huni kuin hiwepaunibuki: a história dos caxinauás por eles mesmos. La historia de los cashinahuas por ellos mismos. São Paulo: Edições SESC, 2013. p. 31.

COMRIE, Bernard. Apresentação. In: CAMARGO, Eliane. VILLAR, Diego (Org.). Huni kuin hiwepaunibuki: a história dos caxinauás por eles mesmos. La historia de los cashinahuas por ellos mismos. São Paulo: Edições SESC, 2013. p. 17-19.

DOCUMENTAÇÃO DE LÍNGUAS AMEAÇADAS (DOBES). Cashinahua. A documentation of Cashinahua language and culture. [S.l.]: Projeto DOBES, 2006-2011. Disponível em: <http://dobes. mpi.nl/projects/cashinahua/?lang=pt> . Acesso em: 8 abr. 2016.
LEWIS, M. Paul; SIMONS, Gary F; FENNIG, Charles D. (Ed.). Ethnologue: languages of the world. 19. ed. Dallas, Texas: SIL International, 2016. Disponível em: <http://www.ethnologue. com>. Acesso em: 8 abr. 2016.

RICARDO, Beto; RICARDO, Fany (Ed.). Povos indígenas no Brasil: 2006-2010. São Paulo: Instituto Socioambiental, 2011.

SEIDLER, Christoph; LUBBADEH, Jens. Neuentdeckter Indianerstamm: "Das kann der Anfang vom Ende sein". Spiegel Online, 30 maio 2008. Disponível em: <http://www.spiegel.de/ wissenschaft/natur/neuentdeckter-indianerstamm-das-kann-deranfang-vom-ende-sein-a-556720.html>. Acesso em: 8 abr. 2016.

REITER, Sabine. Acabou o tempo dos mitos? Uma historiografia caxinauá moderna. Boletim do Museu Paraense Emílio Goeldi. Ciências Humanas, v. 11, n. 2, p. 537-540, maio-ago. 2016. DOI: http://dx.doi.org/10.1590/1981.81222016000200011.

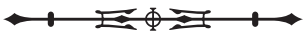

